\title{
Reviewing the Focus:
}

\section{A Summary and Critique of Child-Focused Sexual Abuse Prevention}

\begin{abstract}
Due to the high incidence, and widespread detrimental health consequences, of child sexual abuse (CSA), effective prevention remains at the forefront of public and mental health research, prevention and intervention agendas. To date much of the focus of prevention has been on school-based education programs designed to teach children skills to evade adult sexual advances, and disclose past or ongoing abuse. Evaluation of sexual abuse prevention programs demonstrate their effectiveness in increasing children's knowledge of CSA concepts and protection skills, but little is known about their effects on children's capacity to prevent abuse. Moreover, concerns persist about the unintended side-effects for young children such as anxiety, worry and wariness of touch. This paper summarizes the recent history of CSA prevention and the critique of child-focused protection programs in order to demonstrate the need to compliment or replace these programs by focusing more on protectors in the children's ecology, specifically parents, in order to create safer environments in which abuse is less likely to occur.
\end{abstract}




\section{Reviewing the Focus:}

\section{A Summary and Critique of Child-Focused Sexual Abuse Prevention}

Due to the high incidence and detrimental health consequences of child sexual abuse (CSA), effective prevention is of utmost importance. The extremely high and persistent level of public concern regarding CSA from the late 1970s onwards, and the general lack of alternative program options to aid prevention, has led to the widespread adoption of schoolbased education programs aimed at increasing children's knowledge of CSA risks and building their self-protective skills (Daro, 1994; Prescott, Plummer, \& Davis, 2010; Renk, Liljequist, Steinberg, Bosco, \& Phares, 2002; Wurtele, 2009). Evaluation studies have shown increases in children's knowledge of CSA concepts and self-protection skills following program completion. However the methodological limitation of the majority of evaluation studies must be taken into consideration (Davis \& Gidycz, 2000; Topping \& Barron, 2009; Walsh, Zwi, Woolfenden, \& Shlonsky, 2015). Furthermore it is unknown whether this increase in children's knowledge and skills is effective in reducing the real incidence of CSA (Finkelhor, Asdigian, \& Dziuba-Leatherman, 1995; Ko \& Cosden, 2001; Pelcovitz, Adler, Kaplan, Packman, \& Krieger, 1992).

Despite the absence of clear evidence of their capacity to protect children in real-life abuse scenarios, CSA prevention programs have secured widespread public support and financial commitment due to their low cost and their ability to reach large numbers of children easily and efficiently (Prescott et al., 2010; Wurtele, 2009). This paper attempts to respond to calls over the last few decades from both critics and advocates of these programs for an increased involvement of parents in CSA prevention (Finkelhor \& Dziuba-Leatherman, 1995; Gilbert, Berrick, LeProhn, \& Nyman, 1989; Reppucci, Haugaard, \& Antonishak, 2005). The theoretical underpinnings for this approach lies in the proximal position parents occupy in a child's ecology. This position allows them to create safer environments for their 
children, in which sexual approaches by adults are less likely to occur, and to ensure that their children are more difficult targets for CSA offenders through adequate parenting practices, familial relationships, monitoring and communication (Kaufman, Barber, Mosher, \& Carter, 2002; Wortley \& Smallbone, 2006). The aim of this paper is to demonstrate the need for this shift by summarizing the historical trajectory of child-focused prevention and to present a critique of this approach.

\section{Recent Historical Overview of CSA}

Understanding current perspectives and approaches to reducing CSA requires some consideration of CSA prevention's history. It has been argued that Freud's renunciation of his radical seduction theory, which directly implicated CSA in adult emotional ill-health, played an early role in shaping society's approaches to prevention, and paved the way for the denial of CSA, and its harmfulness, that characterized a significant part of the $20^{\text {th }}$ century (Masson, 1992; Olafson, Corwin \& Summit, 1993; Smaal, 2013). Possibly in response to criticism Freud received from colleagues and mentors, Freud's seduction theory, with its extrapsychic aetiology, morphed into the intrapsychic Oedipus complex. Some feminist thinkers trace society's denial of victims' experience of sexual abuse to the Oedipus complex, which they claim reformulated CSA into a figment of the victim's imagination, resulting in its suppression as a focus of research or prevention efforts for most of the $20^{\text {th }}$ century (Russell, 1999; Masson, 1992; Smaal, 2013). However, Angelides (2004a) stresses that Freud repudiated not the seduction theory in its entirety, but the sole etiological significance of sexual abuse in adult mental health. As many sexually abused children did not develop hysterical symptoms, Freud theorized that abuse causes pathogenic effects only later in life when it is coupled with other pre-conditions such as unconscious memories. Olafson, Corwin and Summit (1993) write about the 'cycles of discovery and suppression' of CSA in modern history, featuring ambivalence and conflict about adult-child sexual relations (p. 7). Likewise, 
Jenkins (2004) highlights the cyclical nature of CSA, with public and political concern peaking in 1915, 1935 and the mid-1970s, continuing to the present day. Smaal (2013) suggests that professionals and practitioners were contemplating and rethinking the problem between 1910 and 1970 rather than ignoring it.

In 1953 Alfred Kinsey's controversial 'Sexual Behavior in the Human Female' was published (Kinsey, Pomeroy, Martin, \& Gebhard, 1953). Described as an authentic study of the biological, psychological and social factors of female sexual experience, the book includes a section entitled 'Pre-adolescent Contact with Adult Males.' The title reveals the conceptualization of CSA by Kinsey and his colleagues; "If a child were not culturally conditioned it is doubtful if it would be disturbed by sexual approaches of..[an adult]" (p. 121), and may reflect societal views of child sexuality and intergenerational sex at that time (Angelides, 2004a; 2004b; Jenkins, 2004).

In the late 1970s and early 1980s, the concept of child-adult sex was revolutionized by feminist theorists and writers (e.g. Armstrong, 1978; Herman, 1981). Feminist scholars labelled child-adult sexual contact as 'abuse', placing it within a patriarchal framework, where unequal power divisions, and male control in the private sphere, facilitate the sexual exploitation of (mostly female) children by (male) adults, causing significant harm in the process. Building on these views, the early 1980s saw the publication of studies suggesting that CSA was far from rare. For example, Russell (1983) reported that 38\% of 930 North American women interviewed in 1978 had experienced contact sexual abuse in childhood and adolescence ( $28 \%$ before the age of 14$)$. Similarly, in another study from the U.S. published about the same time, $44 \%$ of 248 women reported contact CSA before the age of 18 (Wyatt, 1985).

These high prevalence figures and several high profile cases (such as the Cleveland child abuse scandal in the UK in 1987 and the McMartin preschool trial in the US the same 
year) caused public outrage and panic (Angelides, 2004b; Olafson et al., 1993; Prescott et al., 2010; see Jenkins, 2004, for overview of child molestation and moral panic). Attention turned to governments and professionals to rectify the problem as a matter of urgency.

\section{Response to CSA and Intervention Aimed at Children}

As is often the case when public and political concern is high, the desire to act resulted in interventions preceding knowledge and theory generation. Central to prevention efforts was a novel approach, which was based on empowerment and self-defense concepts of the women's anti-rape movement, of educating children in how to protect themselves from the sexual advances of adults (Swift \& Ryan-Finn 1995; Tutty 1997; Zwi, Woolfenden, Wheeler, O'Brien, Tait, \& Williams, 2008), because "adults are not always able to provide complete supervision and protection for children" (Plummer, 1999, p. 78). Beginning in the late 1970s, these "new and untested" (Plummer, 1999, p. 78) interventions were provided to children in the school setting. By 1993 67\% of US schools had received such an intervention, and millions of children had undergone CSA education in the U.S. by the end of the century (Finkelhor \& Dziuba-Leatherman, 1995; Plummer, 1999).

Academic interest in the field flourished and throughout the 1980s and 1990s CSA research burgeoned in the U.S. (Conte, 1994; Smaal, 2013), with several journals devoted to it (e.g. 'Sexual Abuse: A Journal of Research and Treatment' and the 'Journal of Child Sexual Abuse' founded in 1988 and 1992 respectively). Mandatory reporting was introduced in the U.S. and government funding increased substantially. For example, in the late 1980s the state of California (USA) was spending over $\$ 10$ million a year to fund prevention training for public school children and had allocated millions for children to receive CSA education five times during their schooling (Melton, 1992; Plummer, 1999; Finkelhor \& Strapko, 1992). According to Armstrong (2000) the 'CSA industry' was born. 
Awareness of CSA was marginally preceded by the recognition of physical abuse and neglect (Kempe \& Kempe, 1978; Olafson et al., 1993). However, CSA prevention has followed a different trajectory to the prevention of other forms of abuse; targeting potential victims rather than potential perpetrators and protectors. In effect, rather than addressing adult behavior change, as with other forms of child abuse, CSA prevention has emphasized child behavior change (Daro, 1994; Finkelhor, 2009; Renk et al., 2002). There are several reasons for this. Firstly, the speed and the intensity of the public's exposure to CSA resulted in the development and implementation of rushed interventions (Daro, 1994; Bolen, 2003). Secondly, preliminary research seemed to show that profiling at-risk children, offenders and families, as is the practice in the physical abuse prevention area, would be difficult. CSA offenders are a wide and varied population ranging in age from adolescents to the elderly, and traversing all racial and socio-economic groups. As victims generally know their abusers, linked by family or community, the victims were shown to be as varied demographically as the offenders. However, since the early years of CSA research, a significant body of knowledge has amassed demonstrating that certain familial and parenting risk factors increase a child's likelihood of experiencing CSA (Fergusson, Lynskey, \& Horwood, 1996; Pérez-Fuentes, Olfson, Villegas, Morcillo, Wang, \& Blanco, 2013). The CSA field has not taken advantage of the prevention opportunities presented by this evidence, possibly deterred by the stigma and social discomfort associated with targeting interventions for those at-risk of sexual victimization.

Thirdly, this same sigma and taboo meant that parents found it difficult to talk to their children about the issue, and they initially appreciated that schools were "filling the information vacuum" (Daro, 1994, p. 200-1). Parents also supported the programs initially because they thought the danger of CSA was found outside the home and that their children could be taught 'stranger danger' (Smallbone, Marshall, \& Wortley, 2008). Fourthly, the 
CSA field has suffered from a disconnect between treatment and prevention. Those involved in physical abuse and neglect prevention were usually the professionals treating families involved in the abuse, whereas CSA prevention has been spearheaded by such varied stakeholders as the rape crisis movement, the women's movement, education, law enforcement, medicine and public health (Daro, 1994; Plummer, 1999).

Lastly, the difficulty in developing voluntary treatment programs for potential offenders resulted in this avenue being woefully underexplored (Beier, Ahlers, Goecker, Neutze, Mundt, Hupp, \& Schaefer, 2009; Finkelhor, 2009; Smallbone et al., 2008). Voluntary treatment is complicated by a lack of community empathy for sexual offenders (which hinders support for publically funded community services for this group); the stigma preventing potential offenders volunteering themselves for treatment; and their risk of prosecution, as the rates of prosecution are higher for sexual compared to physical crimes committed against children (Daro, 1994; Smallbone, et al., 2008).

Despite these difficulties, it may still have been possible to devise more integrative and multifaceted prevention models (encompassing primary, secondary and tertiary interventions and incorporating more of a child's ecology) had research and scholarship been able to keep pace with the sudden public attention, and ensuing demand for action, which has cemented child-focused programs as the centerpiece of sexual abuse prevention in Anglophone countries. The restricted focus of prevention is problematic, and the limited potential offender and parent focus has left the CSA prevention field without the most successful tools used in the prevention of physical abuse and neglect (Renk et al., 2002; Swift \& Ryan-Finn, 1995). Interventions targeting potential offenders, parents and community members are certainly feasible and adopting a wider range of targets in prevention will assist in minimizing any implicit message that children are responsible for their protection from abuse (Smallbone et al., 2008; Swift \& Ryan-Finn, 1995). 


\section{Evaluations of Child Sexual Abuse Prevention Programs}

CSA prevention programs (CSAPP) are predominately school-based. They vary in their delivery, length, age of participants, type of presenter and materials, but most aim to give children the knowledge and skills to empower them to effectively ward off sexual advances and to disclose past or ongoing sexual abuse (Davis \& Gidycz, 2000; Sanderson, 2004; Zeuthen \& Hagelskjær, 2013). CSAPPs are attractive to the prevention field for various reasons. In particular, they are inexpensive (according to Daro, it cost just $\$ 7$ a child to deliver prevention education to California school children in the 1980s). Also, CSAPPs require little of parents or other adults, relieving them of the potential discomfort of addressing the topic with their children, and affording them a sense of security regarding the safety of their children. CSAPPs are also able to reach substantial numbers of children, can be easily replicated and administered, and avoid the stigmatization of targeting individual children or families at risk of sexual abuse (Daro, 1994; Walsh et al., 2013). Yet, in 2016, it is still unclear whether this approach works, for how long it works, and if it causes any unintended harm to children, such as anxiety, worry and fear (Kaufman et al., 2002; Topping \& Barron, 2009; Zeuthen \& Hagelskjær, 2013; Zwi et al., 2008). Furthermore, there is no agreement as to what constitutes effectiveness (Zeuthen \& Hagelskjær, 2013). Evaluations of CSAPPs can involve measuring any or all of the following: knowledge of prevention concepts using questionnaires or interviews, skills associated with prevention using hypothetical scenarios, behavioral responses to simulated situations and disclosure rates. Regardless of which of these are measured, the effectiveness of CSA programs can only ever be ascertained through 'proxy' (Wurtele, 1987), 'intermediate' (Leventhal, 1987) or 'proximal' (Tutty, 1992) means, "presumed to be predictive of skills in the actual situation" (MacMillan, MacMillan, Offord, Griffith, \& MacMillan, 1994, p. 870) and, the ultimate 
question remains - do school based CSAPPs reduce the incidence of sexual victimization of children?

For this summary of the findings, PsycInfo, Medline and Google Scholar were searched (using various combinations of the terms "sexual abuse," "sexual assault," "prevention" and "parents/ing") to identify published meta-analyses and reviews of CSA programs, and evaluations of programs. The manuscripts located revealed that programs do increase children's CSA knowledge and skills. For example, in a meta-analytic evaluation of 27 studies (Davis \& Gidycz, 2000), CSA educated children scored 1SD higher on outcome measures used in the studies (i.e. knowledge based or behavioral outcome measures) than children who had not received CSA education. However, as described by the authors of this meta-analysis, the studies had many methodological problems, with poorer methodologies delivering higher effect sizes. In a more recent analysis, Walsh and colleagues (2015) reported a significant increase in knowledge scores and protective behaviors in a metaanalysis of 24 studies. However the authors were cautious when interpreting the results due to methodological flaws found in most studies. Topping and Barron (2009) also lamented the methodological problems inherent in the 22 evaluations they reviewed, which included a lack of reporting on sampling, attrition, gender distribution and demographics; a lack of fidelity evaluation, control groups, blinding and random sampling; and the use of short, closed measures. They also found that the theoretical underpinning of CSA programs were obscure and many seemed to be atheoretical. They reported that the majority of the studies they reviewed found significant increases in knowledge and/or abuse prevention skills (effect sizes ranging from 0.14 to 1.4 , with an average of 0.61 ), but that over half the studies reported negative side-effects such as anxiety, dependency, fear of strangers, upset and wariness of touch, which must be balanced against any improvements in knowledge that might have accrued among children. Zwi et al. (2008) recommended in their meta-analysis that the harms 
reported in some studies (e.g. anxiety, fear of strangers, nightmares, bed-wetting and school avoidance) should be further investigated and that child-focused interventions only be used as part of a wider community approach.

Disclosure is sometimes measured as an outcome following CSAPPs (Barron \& Topping, 2010; Walsh et al., 2015). Disclosures may cause ongoing abuse to end, and the impact of the abuse to be lessened, constituting tertiary prevention (Barron \& Topping, 2010). Some researchers judge disclosures to be the least ambiguous and most valid indicator of the success of a CSA education program (Finkelhor \& Strapko, 1992; Macmillan et al., 1994). However Topping and Barron (2009) referred to disclosure rates as an "enigmatic outcome indicator" questioning whether a higher rate of disclosures "is necessarily a good thing" (p.449). Data on disclosure rates is limited and methodologically compromised, resulting in a dearth of meta-analytical data (Barron \& Topping, 2010; MacMillan, Wathen, Barlow, Fergusson, Leventhal, \& Taussig, 2009). For example, only three studies in Walsh et al.'s review (2015) reported adequate disclosure information to allow a meta-analysis. This analysis revealed a significant result for disclosure rates (as measured by forms completed by school staff, spontaneous child disclosures and school guidance officer incident reports) and intervention. MacMillan et al. (2009) noted that methodological weaknesses "precluded determining whether such disclosures were associated with the intervention" (p. 254). Gibson and Leitenberg (2000) and Ko and Cosden (2001) found no statistical difference in disclosure rates in their studies, however Gibson and Leitenberg found that CSA program attendees reported disclosing earlier and experienced abuse of a shorter duration. Finkelhor and colleagues (1995a; 1995b) found the more comprehensive CSA education programs increased the likelihood of disclosure among the youth in their study. Briggs and Hawkins (1994) reported that children from low-socio-economic backgrounds were least capable of 
making clear and accurate disclosures, and Kenny and colleagues found disclosure of abuse to be the most difficult skill to learn (Kenny, Capri, Thakkar-Kolar, Ryan, \& Runyon, 2008).

Overall, it seems that CSA education programs are able to improve children's scores on knowledge tests and safe responses to hypothetical vignettes, and may result in more disclosures in some instances. However, whether these programs can assist children in the event of an actual threat of molestation remains unknown (Finkelhor, 2009; Kenny et al., 2008; Tutty, 2000; Zwi et al., 2008). Three U.S. studies have attempted to shed light on this issue by examining the experiences of child participants, albeit retrospectively. In 1995 Finkelhor and colleagues reported on the results of telephone interviews conducted with 1457 nationally representative young people aged between 10 and 16. Exposure to CSA school programs (regardless of program comprehensiveness) did not reduce the incidence of actual completed victimizations, sexual or otherwise. In addition, completion of a program did not prevent injury associated with victimizations. Participation in a more comprehensive program did seem to increase feelings of efficacy in dealing with all types of victimizations, but not sexual victimization specifically (Finkelhor et al., 1995a). In a similar study, Ko and Cosden (2001) asked 137 high school students whether they had attended a CSA program in primary school and their subsequent experiences. Ten percent of the sample reported experiencing CSA but there was no statistical difference between the groups that had or had not attended a CSA program, with $10.7 \%$ of attendees and $9.7 \%$ of non-attendees reporting CSA. It emerged that the majority of children, regardless of attendance status, used recommended prevention strategies to counter abuse. Of the students who had experienced an abusive situation, and used a recommended strategy, $46 \%$ confirmed the strategy had a positive impact by reducing or preventing harm, $43 \%$ reported negative outcomes, and $11 \%$ described a combination of the two. Those children abused by a family member reported less successful use of prevention strategies. 
In a third study, using an older sample, Gibson and Leitenberg (2000) asked 825 female undergraduates about their sexual experiences. Sixty-two percent confirmed that they had participated in a sexual abuse prevention program at school. Of those women, $8 \%$ reported that they had experienced sexual abuse, while $16 \%$ of those that had never attended a program reported having been sexually abused, a difference that was statistically significant. There were no differences in the two groups on levels of sexual activity or satisfaction. All three of these studies obviously suffer from the limitations associated with retrospective data interpretation.

In an examination of actual experiences, twenty-two 6- to 10-year-old victims of long-standing abuse by a school employee did not disclose their abuse despite participating in a school based CSAPP in a film format (Pelcovitz et al., 1992). During interviews the children said the film did not help them know how to respond to the abuse. An 8-year-old boy did not find the movie helpful because his abuser was not in the movie and a 7-year-old boy did not tell because he thought his parents would be angry with him. Two 10-year-old girls said they did not disclose due to embarrassment and fear of the perpetrator's threats. They responded with surprise that adults thought the advice in the film to disclose abuse was in any way relevant to their situation, in which they felt coerced by an adult in authority: "I was just too afraid to make decisions," (Pelcovitz et al., 1992, p. 890). Although this study utilized possibly the least effective form of conveying information to children (i.e. a film format), these children's testimonies suggest we may need to reconsider to what extent children are able to use the information given in CSAPPs in real life abuse situations.

As mentioned consistently by reviewers of the literature, CSAPP evaluations often have methodological limitations, such as a lack of control or comparison groups, blinding, appropriate randomization, fidelity control, small samples and measurement issues (Davis \& Gidycz, 2000; Macmillan et al., 1994; MacMillan et al., 2009; Sanderson, 2004; Topping \& 
Barron, 2009; Zwi et al., 2008). Other caveats to consider when interpreting findings are small effect sizes, ceiling effects and differential learning of concepts (Leventhal, 1987; Topping \& Barron, 2009; Tutty, 1997, 2000).

Great faith was placed in child focused CSAPPs in the early years. Without evidence to suggest molestation rates could be reduced by children themselves, claims to this effect were being made, such as: "Ten years ago, educators in Canada and the USA began to realize that much child sexual molestation could be avoided if children from $2-3$ years upwards were given comparatively simple information relating to inappropriate touching. It was realized that children's lack of knowledge about the norms of adult-child behavior" put them in danger of abuse (Briggs, 1988, p. 170). This reflects a major criticism of school based CSAPPs, namely that they place the onus of protection on to the victims themselves. These criticisms, and others, are discussed in the following section. Briggs (1988) justifies targeting children because there is, "no incentive for abusers to seek treatment [and] there are not enough treatment programs available" (p. 170). This suggests complacency, that the lack of potential offender treatment programs, and parent/teacher/community education initiatives are considered too difficult and/or complex to be funded, researched or implemented.

\section{Summary of the Criticisms of CSA Prevention Education for Children}

Primary prevention is crucial in reducing the incidence of CSA. However, it is also necessary to identify the most appropriate targets for primary prevention, to measure both intended and possible unintended outcomes of interventions, and for the assumptions on which interventions rest to be clearly delineated. These issues have been addressed in critiques of CSA education for children. Key points are summarized here to argue for a greater emphasis on CSA prevention initiatives that focus on adults as protectors, especially parents. 
Appropriateness of the focus on children. Critics have questioned the appropriateness of targeting young children (usually 3- to 10-year-old) for sexual abuse prevention, arguing that it is unrealistic to expect young children to defend themselves against the social, psychological and physical manipulations used by perpetrators (Berrick \& Gilbert, 1991; Daro, 1994; Kaufman et al., 2002; Melton, 1992; Reppucci et al., 2005). The expectation that children are able to protect themselves from abuse it is not an expectation in the prevention of other forms of child maltreatment (Renk et al., 2002; Smallbone et al., 2008; Wurtele, 2009) and rests on several assumptions. First, research shows abuse usually begins with unobtrusive gestures and touches in the context of a relationship characterized by care, affection and/or friendship (Berliner \& Conte, 1990; Smallbone \& Wortley, 2000). To protect themselves, children must be able to identify subtle actions or signals as abusive. However, it is questionable whether young children are able to determine whether a touch is good or bad or confusing. Indeed, significant numbers of adults are unable to distinguish between "a friendly pat, an affectionate hug or a sexual advance" (Berrick \& Gilbert, 1991, p. 110). These labels may also be meaningless in some abusive scenarios where victims have not found exploitative touches to be painful, bad, not-ok or confusing (Berliner \& Conte, 1990; Herman, 1981; Russell, 1999). This is significant as most modern protective behavior programs focus on warning signs and safe and unsafe situations, which may not be recognizable or relevant to some children (e.g. the Talking about Touching and Good touch/Bad touch programs).

Second, children must be able to challenge the authority of an adult (possibly a family member, someone the child cares about or relies on, or someone who holds a position of authority). The child must be able to reject the unwanted contact and, the child may be required to psychologically counter the perpetrator's threats and forego unmet needs or desires. Negotiating the psychological manipulations of an adult intent on exploiting them 
may be beyond the capacity of a young child's mental and emotional ability and stamina. The study by Pelcovitz et al (2002), mentioned previously, demonstrated the ability of someone in authority (a school auxiliary) to manipulate non-disclosure. Studies with offenders have shown they are not easily deterred by children's resistance (Conte, Wolf, \& Smith, 1989; Elliot, Browne, \& Kilcoyne, 1995). For example, although Leclerc, Wortley and Smallbone (2010) found 'saying no' to be a strategy that, "may have been able to avoid episodes of abuse," all victims were, "sexually abused by the offender at some point" (p. 1879). Likewise, women in Russell's (1983) study reported having to ward off their assailants repeatedly over a period of years. Kaufman \& Harbeck-Weber (1994) suggest that an offender's decision to target a particular victim "was related to factors that may be difficult to address in prevention programs for children" (p. 354).

Third, children must be able to report the abuse. This capability, again, requires the child to overcome the offender's threats, the confusing nature of the abuse, and internal barriers, in order to report the actions of an adult. Many adults experience abusive or exploitative scenarios that they fail to report, not through lack of knowledge, but due to the extremely complex nature of interpersonal relationships and social contexts.

In addition, targeting the victims of abuse does not prevent the attempted initiation of sexual contact by an adult. This sexual approach, possibly by a loved one or someone in authority, may cause the child harm in itself, and is associated with psychological, social and emotional fallout when the child resists and disclosures. Targeting parents (or other adults) as protectors presents an opportunity to prevent situations arising where children are required to enact protection strategies, thereby avoiding the potential harm of these situations. Moreover, critics suggest that relying on young children to avert abuse shifts the burden of responsibility for protection from the adult community onto the children themselves (Berrick \& Gilbert, 1991; Melton, 1992; Smallbone et al., 2008). For as long as child focused interventions 
remain at the forefront of prevention, the adult community is somewhat relieved of their duty as child protectors.

CSA prevention advocates have begun to acknowledge this as a problem and have addressed these criticisms with adjustments in terminology. For example, Kenny and colleagues (2008) recommend replacing the term 'prevention' with terms such as personal safety skills, abuse-response skills or self-protection skills, in order to avoid the impression that children are responsible for the reduction or prevention of CSA. Kenny and colleagues describe an agreement among professionals that the aim of CSAPPs is not "intended to place the responsibility of limiting the seriousness of assaults on children but rather to provide children with information that may increase the likelihood of disclosure and of obtaining a supportive response from caregivers. Programs should avoid the use of 'good and bad touch', but rather use 'okay' and 'not okay' touch" (2008, p.47). According to Kenny and colleagues, this semantic shift is intended to teach children that not all sexual touching is negative and limit the possibility that children who have experienced 'bad' touches feel that they are 'bad' in themselves. It seems questionable whether children seeing themselves as 'not ok' is psychologically healthier. Reppucci et al (2005) suggest re-branding CSAPPs as 'disclosure programs' if that is their intended purpose.

In summary, targeting children in CSA prevention is not without its problems and there is a need to focus on adults in CSA prevention - namely potential offenders, and protectors (parents, teachers, medics, clinicians and community members). As Wurtele (2009) notes, "the obvious approach to injury prevention is to educate parents about safe homes, not by teaching children to stay away from poisons, bathtubs or window ledges. We need to utilize the same strategy for CSA prevention. Given that the family is the most proximal level of the child's ecology it makes sense to focus on it first” (p. 10). 
Unintended outcomes. Another criticism of targeting children for CSA prevention is the unintended consequences of the intervention, for the children themselves, for the protection of children, and for the prevention of CSA as a whole. First, regarding the unintended outcomes for children, the psychological consequences of informing children that they are potential targets of abuse and, even more significant, at the hands of parents, extended family and loved ones, should be considered. According to Berrick and Gilbert, the version of the Talking about Touching program delivered in the 1980s used the scenario of a young girl being tucked into bed by her father to illustrate what children should do if the father touches her inappropriately. It is hard to imagine that this 'danger' would ever be conceived by the child on their own and "no matter how sensitively this is presented this is a disturbing message delivered at a time in children's lives when it is important to have a sense of trust that parents and caregivers will nurture and protect them," (Berrick \& Gilbert, 1991, p. 110). Although the early Talking about Touching program is an extreme example, modern protective behavior programs continue to introduce children to the concept that loved family members may be unsafe (https://www.youtube.com/watch?v=BgnlobZlHg8, https://www.youtube.com/watch?v=NAZWaxNXA-4).

Some children find CSAPPs frightening and anxiety provoking. Over half the studies reviewed by Topping and Barron (2009) reported some negative effects (such as anxiety, fear of strangers, aggression, upset and wariness of touch) the majority of which were reported to be mild in nature, of short duration and small in number. Only three studies in one review (Zwi et al., 2008) compared adverse effects between treatment and control groups. Some harms reported were: $13-25 \%$ being more fearful of strangers, increased dependency behaviors (13\%) and 5\% having adverse reactions such as bed-wetting, nightmares, crying and school refusal. According to post-CSAPP parent reports in MacIntyre and Carr's (1999) study, $23 \%$ of children were more wary of touches, $6 \%$ were more wary of strangers, and $2 \%$ 
used learned strategies inappropriately. Likewise, teachers reported $16 \%$ of children were more anxious, that $6 \%$ of children had found the lessons dealing with private parts and being touched by a relative as upsetting, and $11 \%$ used learned strategies inappropriately. Ten percent of the children themselves reported being upset by aspects of the program. The authors caution that these results should not be interpreted as unduly negative, as the children "who become more wary of touches and strangers developed good self-protection skills" (p. 1322), with parents and teachers still strongly supportive of the program. Fifty-three percent of children in a large telephone survey reported that they worried about being abused, $9 \%$ worried about being abused by a family member, and $20 \%$ were scared by adults after a CSA intervention (Finkelhor \& Dziuba-Leatherman, 1995). Like MacIntyre and Carr, the authors conclude that these fears and anxieties may be adaptive. Although reported disproportionally amongst possibly the more vulnerable children (the younger and lower SES), these children and their parents also evaluated the program most favorably (Finkelhor \& DziubaLeatherman, 1995). Gilbert et al. (1989) found that post-CSAPP children associated ambiguous touch experiences such as bathing and tickling with negative emotions such as feeling sad. In contrast to these findings, some studies have demonstrated no adverse effects of CSAPP attendance (for example, Binder \& McNiel, 1987; Dale, Shanley, ZimmerGembeck, Lines, Pickering, \& White, 2016; Hazzard, Webb, Kleemeier, Angert, \& Pohl, 1991). Participants in Gibson and Leitenberg's (2000) retrospective study self-reported no difference in sexual satisfaction between CSAPP attendees and non-attendees. However, enough evidence of harmful effects exists to warrant a re-evaluation of the universal use of child-focused CSA interventions as the sole, or leading, prevention initiative, and to consider investing in initiatives targeting adults, especially parents.

Second, regarding outcomes for protection and prevention, CSA prevention as a whole may be impaired by the focus on school based programs. While these programs are 
being prioritized, other, potentially more effective and safer forms of reducing the incidence of CSA, are being under-resourced and under-utilized (Beier et al., 2009). Indeed Renk et al (2002) suggest that targeting children rather than offenders is sending a dangerous message that changing offender behavior is too difficult and that it is useless to intervene at other levels. Smallbone et al. (2008) agree, suggesting that this focus is due to a false belief that efficacious programs for abusers cannot be implemented until potential abusers have begun to offend, and children have been subjected to CSA. In addition, some critics maintain that school-based programs may be making children less safe by lulling parents and the community into a false sense of security about the ability of CSAPPs to protect children from abuse, resulting in lower levels of protective behaviors by adults (Berrick \& Gilbert, 1991; Sanderson, 2004).

In critiquing CSAPPs, the question at the foreground continues to be the feasibility of children transferring to real life scenarios any increase in knowledge gained from programs designed to decrease the incidence of abuse. The critique presented in the current paper demonstrates the need to shift the focus to adults - potential offenders, and protectors (parents, teachers, medics, clinicians and community members). Targeting these groups has the potential to stop abuse before it occurs; even before a child is approached in a sexual manner.

\section{Adults as Protectors: Reviewing the Focus of Prevention}

CSA occurs as a complex interaction of a multitude of individual and contextual factors, requiring "an entire spectrum of necessary prevention strategies applied over time" (Daro, 1944; Prescott et al., 2010, p.3; Swift \& Ryan-Finn, 1995). Finkelhor (1984) has identified four pre-conditions that must be present for CSA to occur:

1. A motivated perpetrator.

2. A perpetrator with the ability to overcome internal inhibitions regarding CSA. 
3. A perpetrator that has the ability to overcome external barriers to committing CSA.

4. A victim unable to resist the abuse.

Finkelhor's integrative conceptualization of CSA (and others like it) demonstrates that a multifaceted prevention approach is required and identifies numerous opportunities for the prevention of abuse. A possible approach is the ecological model, which intervenes at the individual, relationship, community and societal levels, integrating the perpetrator and victim in their social, cultural and economic contexts (Bronfenbrenner, 1977). Although all responsible adults could play some role in protecting children from abuse, parents and the home environment are the most significant parts of a child's ecology. Parents' can play a critical role as protectors of their children via two pathways: directly, through strong external barriers afforded by parent supervision and monitoring (Finkelhor's precondition 3) and, indirectly, through child well-being derived from adequate parenting practices, familial relationships and communication (precondition 4).

Key CSA prevention campaigners and researchers have long promoted the crucial role parents can play in keeping children safe (Gilbert et al., 1989; Kaufman et al., 2002; Reppucci et al., 2005; Wurtele, 2009). Despite this, the involvement of parents has been limited, and the focus has been on parents' protection of their children through education about the dangers of CSA. Parents are, indeed, in a good position to do this, as the home environment lends itself well to situational learning experiences and information rehearsal, and because parents are more likely to be trusted and believed by their offspring. However, the most significant parental contribution is parents' capacity to prevent abuse from occurring by creating safer environments for their children (Smallbone et al., 2008; Wurtele, 2009) and raising children that are less likely to be targets for sexual offenders. It is this aspect of parental involvement in prevention that has been under-examined and therefore underutilized in CSA prevention. 
Parenting and CSA risk factors. The research addressing parenting and CSA prevention has focused largely on parental involvement in school-based programs (Sanderson, 2004; Tutty, 2000) and parental discussions of CSA within the home (Briggs, 1988; Kenny at al., 2008; Walsh, Brandon, \& Chirio, 2012) with the ultimate focus still being the fourth of Finkelhor's preconditions - making the child more resistant to sexual victimization. What is lacking in CSA prevention research is a clearer picture of problematic or protective day-to day-behaviors that parents engage in that may have implications for their children's CSA risk. To gain a better understanding of parents' role as protectors in this area, the wider CSA literature must be examined.

The main findings in the literature regarding the risk factors of CSA, suggest that while no environmental, parental or child factors may be used to confirm or disconfirm actual cases of abuse, there are characteristics, especially related to family structure and parenting, that are associated with greater risk (Fergusson et al., 1996; Pérez-Fuentes et al., 2013). Research on parenting deficits and offspring CSA exposure has identified a substantial number of risk factors related to the family that could be targeted by prevention initiatives. Overall, three significant overarching themes can be extracted, which can be used to develop practices for working with parents to improve their knowledge and child protective practices.

The first theme is non-optimal parental supervision and/or monitoring. For example, Testa, Hoffman and Livingston (2011) found mothers' lack of monitoring of their adolescent's activities was associated with their daughters' sexual victimization. Finkelhor and colleagues (1997) reported one significant predictor of a child being sexually abused was parents admitting to having left the child home alone without adequate supervision.

Finkelhor, Ormrod, and Turner (2007) also found that lack of parental monitoring increased the rates of victimization. A lack of supervision/monitoring could also arise from other research-backed risk factors such as parental absence (Herman, 1981; Leifer, Kilbane, \& 
Kalick., 2004), parental physical or mental illness (Brown, Cohen, Johnson, \& Salzinger, 1998; McCloskey \& Bailey, 2000), parental alcohol and substance use (Leifer et al., 2004; McCloskey \& Bailey, 2000) and child neglect (Laaksonen, Sariola, Johansson, Jern, Varjonen, von der Pahlen, Sandnabba, \& Santtila, 2011; Pérez-Fuentes et al., 2013). Parental attitudes that may contribute to a lack of supervision are permissive parenting and liberal sexual attitudes, which have also found to be risk factors for sexual victimization (Meston, Heiman \& Trapnell, 1999; Testa et al., 2011). Other adversities associated with CSA risk, such as marital conflict (Edwards \& Alexander, 1992; Fergusson et al., 1996) and violence (McCloskey \& Bailey, 2000; Ramirez, Pinzon-Rondon \& Botero, 2011) could overwhelm parents' ability to afford appropriate levels of supervision. A finding by Davies and Jones (2013) that the foremost risk factors for sexual victimization for teens was their use of drugs and alcohol and their participation in previous consensual sexual intercourse, also underscores the role of supervision in CSA risk.

A second theme is lack of warm and involved parenting practices. A lack of parental warmth and involvement can be inferred from various CSA risk factors that have been identified, such as poor parent-child relationships (Black et al., 2001; Roberts et al., 2004), low levels of family support (Pérez-Fuentes et al., 2013), low levels of maternal attachment and bonding (Fergusson et al., 1996; Lewin \& Bergin, 2001), higher incidence of neglect (Laaksonen et al., 2011; Pérez-Fuentes et al., 2013), emotional and physical abuse (Fergusson et al., 1996; Kim, Noll, Putnam, \& Trickett, 2007), and parental mental ill-health (Brown et al., 1998; McCloskey \& Bailey, 2000). Brown and colleagues' prospective (1998) study also found that unwanted pregnancy was a significant risk factor for CSA.

A third theme is related to poor communication between parents and children. Ramirez, Pinzon-Rondon, and Botero (2011) found parent-child communication was a strong protective factor against CSA with households where "parents routinely ask questions and 
listen to their children significantly less likely to become victims of sexual abuse" (p. 1029). Likewise, Testa et al (2011) found a mother's communication effectiveness was protective against her daughter's victimization. Parents' lack of effective communication can also be inferred from the higher incidence of neglect, emotional and physical abuse found in families where children have experienced CSA (Fergusson et al., 1996; Kim et al., 2007; Laaksonen et al., 2011; Pérez-Fuentes et al., 2013). Parental absence, death, divorce, mental ill-health or substance use may also limit the amount of effective parent-child communication taking place in households affected by CSA (Fergusson et al., 1996; Leifer et al., 2004; Herman, 1981; Pérez-Fuentes et al., 2013).

This brief summary of CSA risk factors underscores the essential role adults, but particularly parents, can play in child sexual abuse prevention. Viewing parents as protectors places them at the centre of prevention, and adds to the argument that broadening the focus on prevention efforts to include parents, if not all adults, deserves increased attention.

Evidence also exists that rates of child sexual assault are higher in some communities that others (Mustaine, Tewksbury, Huff-Corzine, Corzine, \& Marshall, 2014; Tewksbury, Mustaine \& Covington, 2010). Although many parents may not have much choice over where they live, families living in some communities may need extra support in protecting their children from abuse due to the social disorganization and higher rates of sexual assault found in their neighborhoods. Community-based initiatives to provide knowledge and resources to families may be particularly important. For example, reports from a unique neighborhood-based initiative in one state in the USA, "Strong Communities for Children," show promising results for community intervention in increasing child protection and positive parenting (McLeigh, McDonell \& Melton, 2015).

\section{Conclusion and Recommendations}


Although CSA occurs for many reasons, very few would argue that parents do not play an important role in their children's protection from CSA. Despite some thinkers in the CSA prevention area acknowledging that parental protection goes beyond parent-child discussion of sexual abuse, to include parenting styles and practices, this prevention focus remains under-utilized (Wortley \& Smallbone, 2006; Wurtele, 2009).

Parents can help to protect their children directly by building safer environments as involved and attentive parents - interested and connected to their children in their day-to-day lives, mindful of the importance of monitoring, communication and strong relationships. Such a notion leads directly to the need for CSA protection to be integrated into existing parenting programs. Such a strategy would include CSA modules designed to help parents to better recognize offender tactics and modus operandi and potentially risky situations, at the same time as they assist parents to think of strategies to become more involved and connected with their children in order to create a safer environment. Such topics would be best provided together with addressing other complexities of parenting - we believe it would be most effective (and thereby potentially protective) if such CSA modules are integrated into existing and parent behavioral skills training programs or other similar parenting interventions.

In order to make use of the knowledge we have of risk factors, it is important that the taboo and stigma associated with helping parents protect their children is reduced. Incorporating protective parenting into mainstream parenting programs will strengthen the view of it as an essential and normal part of effective parenting that all parents can benefit from learning about. As the research on CSA antecedents shows, certain parenting practices and home environments place children at greater risk of experiencing abuse. Therefore, the greatest impact on prevention may be made by targeting these parents. We suggest that all parenting programs offered through, or mandated by, child safety or health services should 
contain a CSA component. Such a parenting program should also be offered to young or vulnerable pregnant women during their ante-natal care.

Evaluation of these add-on CSA programs should occur together with evaluation of the parenting program. Due to what is known about risk factors, it can be inferred that parents who display improvements in parenting practices such as communication, involvement and monitoring may decrease their child's CSA risk. Changes in parental knowledge and parental understanding of the risks, and the effects of their parenting, can be measured. Research on health behavior modification suggests that behavior can change through increases in knowledge (Noar, Benac \& Harris, 2007; Sanders, Montgomery \& Brechman-Toussaint, 2000; Wakefield, Loken \& Hornik, 2010). Possible long term follow-up could give an indication of whether the risks of CSA have been reduced, however it may be difficult to isolate the add-on component in these investigations.

All parents would benefit from knowing how their parenting impacts on their children's risk and how to best protect their children. A large proportion of parents could be reached through mass media campaigns (television, radio, internet), by requiring public schools to send home information packs at regular intervals in a child's schooling, and including CSA education for parents with every antenatal information pack given to expectant parents during their hospital care. It may be possible to add a brief summary of CSA risk factors and offender modus operandi into government-run antenatal classes. Although information dissemination is not as effective as comprehensive training programs, research suggests that such campaigns do enact behavior change (Noar et al., 2007; Sanders et al., 2000; Wakefield et al., 2010).

Current knowledge puts parenting and familial circumstances at the forefront of CSA risk. Embracing this knowledge and tailoring prevention to reflect this risk would allow CSA 
prevention to broaden its focus from child-focused programs to include parent-focused prevention of CSA.

\section{Critical Findings}

- Evaluation research demonstrates that child-focused programs increase children's CSA knowledge and protection skills.

- Most program evaluations of child-focused programs have methodological limitations.

- Studies of participants' historical experiences have found program attendance has not prevented victimization.

- Parents can play a crucial role in prevention by creating safer environment and engaging in parenting behaviours that lead to child well-being.

- Risk factors for CSA include a lack of parental monitoring and involvement, and poor parent-child communication.

\section{Limitations of Child-Focused CSA Prevention}

- Child-focused CSA prevention programs were implemented without evidence of their effectiveness.

- There is no evidence to suggest that children's CSA knowledge and prevention skills are transferrable to real-life abuse scenarios.

- Child-focused programs are victim, rather than perpetrator, focused. This is not the case with physical or emotional abuse prevention.

- Some skills taught in child-focused programs may be unrealistic for children to implement.

- There are few tests for possible iatrogenic effects of child-focused programs, but some have found unintended negative outcomes for children such as anxiety, worry about abuse and wariness of touch.

\section{Implications for Policy, Practice and Research}

- The lack of evidence that child-focused programs help children to avoid abuse requires more efforts to rigorously evaluate the widespread use of these programs.

- CSA prevention and protection information and skills training for parents should become part of all parenting programs.

- Those working with vulnerable families should be aware of the risk factors of CSA and work with parents to better protect their children. 
- Future research needs to move beyond parental discussion of CSA with their children as the focal point of CSA prevention, to the role of parenting behaviours such as communication, monitoring and involvement.

- Further research should evaluate the effect on protective parenting behaviours of parenting programs with a CSA component. 


\section{References}

Angelides, S. (2004a). Feminism, child sexual abuse, and the erasure of child sexuality. GLQ: A Journal of Lesbian and Gay Studies, 10, 141-177. doi:10.1215/10642684-10$2-141$

Angelides, S. (2004b). Historicizing affect, psychoanalysing history: Pedophilia and the discourse of child sexuality. Journal of Homosexuality, 46, 79-109. doi:10.1300/J082v46n01_02

Armstrong, L. (1978). Kiss Daddy Goodnight. New York: Hawthorn.

Armstrong, L. (2000). What happened when women said 'incest'. In Itzin, C. (Ed.),. Home Truths About Child Sexual Abuse: Policy and Practice. New York: Routledge.

Barron, I. G., \& Topping, K. J. (2010). School-based abuse prevention: Effect on disclosures. Journal of Family Violence, 25, 651-659. doi:10.1007/s10896-010-9324-6

Beier, K., Ahlers, C., Goecker, D., Neutze, J., Mundt, I., Hupp, E., \& Schaefer, G. (2009). Can pedophiles be reached for primary prevention of child sexual abuse? First results of the Berlin Prevention Project Dunkelfeld (PPD). Journal of Forensic Psychiatry \& Psychology, 20, 851-867. doi:10.1080/14789940903174188

Berliner, L., \& Conte, J. R. (1990). The process of victimization: The victims' perspective. Child Abuse \& Neglect, 14, 29-40. doi:10.1016/0145-2134(90)90078-8

Berrick, J. D., \& Gilbert, N. (1991). With the best of intentions: The child sexual abuse prevention movement. Guilford Publications: New York.

Binder, R. L., \& Mcniel, D. E. (1987). Evaluation of a school-based sexual abuse prevention program: Cognitive and emotional effects. Child Abuse \& Neglect, 11, 497-506. doi:10.1016/0145-2134(87)90075-5 
Black, D. A., Heyman, R. E., \& Smith Slep, A. M. (2001). Risk factors for child sexual abuse. Aggression and Violent Behavior, 6, 203-229. doi:10.1016/S13591789(00)00023-9

Bolen, R. M. (2003). Child sexual abuse: Prevention or promotion? Social Work, 48, 174185. doi:10.1093/sw/48.2.174

Briggs. F. (1988). South Australian parents want child protection programs to be offered in schools and preschools. Early Child Development and Care, 34, 167-178. doi: $10.1080 / 0300443880340112$

Briggs, F., \& Hawkins, R. M. F. (1994). Follow up study of children of 5-8 years using child protection programmes in Australia and New Zealand. Early Child Development and Care, 100, 111-117. doi:10.1080/0300443941000108

Bronfenbrenner, U. (1977). Toward an experimental ecology of human development. American Psychologist, 32, 513-530. doi:10.1037/0003-066X.32.7.513

Brown, J., Cohen, P., Johnson, J. G., \& Salzinger, S. (1998). A longitudinal analysis of risk factors for child maltreatment: Findings of a 17-year prospective study of officially recorded and self-reported child abuse and neglect. Child Abuse \& Neglect, 22, 10651078. doi:10.1016/S0145-2134(98)00087-8

Conte, J. R. (1994). Child sexual abuse: Awareness and backlash. The Future of Children, 4, 224-232. Retrieved from http://www.princeton.edu/futureofchildren/

Conte, J. R., Wolf, S., \& Smith, T. (1989). What sexual offenders tell us about prevention strategies. Child Abuse \& Neglect, 13, 293-301. doi:10.1016/0145-2134(89)90016-1

Dale, R., Shanley, D. C., Zimmer-Gembeck, M. J., Lines, K., Pickering, K., \& White, C. (2016). Empowering and protecting children by enhancing knowledge, skills and well-being: A randomized trial of learn to BE SAFE with Emmy. Child Abuse \& Neglect, 51, 368. 
Daro, D. A. (1994). Prevention of child sexual abuse. The Future of Children, 4, 198-223. Retrieved from http://www.princeton.edu/futureofchildren/

Davies, E. A., \& Jones, A. C. (2013). Risk factors in child sexual abuse. Journal of Forensic and Legal Medicine, 20, 146. doi:10.1016/j.jflm.2012.06.005

Davis, M. K., \& Gidycz, C. A. (2000). Child sexual abuse prevention programs: A metaanalysis. Journal of Clinical Child Psychology, 29, 257-265. doi: $10.1207 /$ S15374424jccp2902_11

Edwards, J. J., \& Alexander, P. C. (1992). The contribution of family background to the longterm adjustment of women sexually abused as children. Journal of Interpersonal Violence, 7, 306-320. doi:10.1177/088626092007003002

Elliott, M., Browne, K., \& Kilcoyne, J. (1995). Child sexual abuse prevention: What offenders tell us. Child Abuse \& Neglect, 19, 579-594. doi:10.1016/01452134(95)00017-3

Fergusson, D. M., Lynskey, M. T., \& Horwood, L. J. (1996). Childhood sexual abuse and psychiatric disorder in young adulthood: I. prevalence of sexual abuse and factors associated with sexual abuse. Journal of the American Academy of Child \& Adolescent Psychiatry, 35, 1355-1364. doi:10.1097/00004583-199610000-00023

Finkelhor, D. (1984). Child sexual abuse: New theory and research. New York: Free Press. Finkelhor, D. (2009). The prevention of childhood sexual abuse. The Future of Children, 19, 169-194. doi:10.1353/foc. 0.0035

Finkelhor, D., Asdigian, N., \& Dziuba-Leatherman, J. (1995a). The effectiveness of victimization prevention instruction: An evaluation of children's responses to actual threats and assaults. Child Abuse \& Neglect, 19, 141-153. doi:10.1016/01452134(94)00112-8 
Finkelhor, D., Asdigian, N., \& Dziuba-Leatherman, J. (1995b). Victimization prevention programs for children: A follow-up. American Journal of Public Health, 85, 16841689. doi:10.2105/AJPH.85.12.1684

Finkelhor, D., \& Dziuba-Leatherman, J. (1995). Victimization prevention programs: A national survey of children's exposure and reactions. Child Abuse \& Neglect, 19, 129139. doi:10.1016/0145-2134(94)00111-7

Finkelhor, D., Moore, D., Hamby, S. L., \& Straus, M. A. (1997). Sexually abused children in a national survey of parents: Methodological issues. Child Abuse \& Neglect, 21, 1-9. doi:10.1016/S0145-2134(96)00127-5

Finkelhor, D., Ormrod, R. K., \& Turner, H. A. (2007). Re-victimization patterns in a national longitudinal sample of children and youth. Child Abuse \& Neglect, 31, 479-502. doi:10.1016/j.chiabu.2006.03.012

Finkelhor, D., \& Strapko, N. (1992). Sexual abuse prevention education: A review of evaluation studies. In Willis, D. J., Holden, E. W., \& Rosenberg, M. S. (Eds.), Prevention of child maltreatment: Developmental and ecological perspectives (pp. 150-167). New York: John Wiley \& Sons.

Gibson, L. E., \& Leitenberg, H. (2000). Child sexual abuse prevention programs: Do they decrease the occurrence of child sexual abuse? Child Abuse \& Neglect, 24, 1115 1125. doi:10.1016/S0145-2134(00)00179-4

Gilbert, N., Berrick, J., LeProhn, N., \& Nyman, N. (1989). Protecting young children from sexual abuse: Does preschool training work? Lexington, MA: Lexington Books.

Hazzard, A., Webb, C., Kleemeier, C., Angert, L., \& Pohl, J. (1991). Child sexual abuse prevention: Evaluation and one-year follow-up. Child Abuse \& Neglect, 15, 123-138. doi:10.1016/0145-2134(91)90097-W 
Herman, J. (1981). Father-daughter incest. Professional Psychology, 12, 76-80. doi:10.1037/0735-7028.12.1.76

Jenkins, P. (2004). Moral panic: Changing concepts of the child molester in modern America. New Haven: Yale University Press.

Kaufman, K., Barber, M., Mosher, H., \& Carter, M. (2002). Reconceptualizing child sexual abuse as a public health concern. In P. A. Schewe (Ed.), Preventing Violence In Relationships: Interventions Across The Life Span (pp. 27-54). Washington, DC: American Psychological Association.

Kaufman, K. L., \& Harbeck-Weber, C. (1994). Re-examining the efficacy of child sexual abuse prevention strategies: Victims' and offenders' attitudes. Child Abuse \& Neglect, 18,349 .

Kempe, R. S., \& Kempe, C. H. (1978). Child Abuse. London: Fontana.

Kenny, M. C., Capri, V., R, R., Thakkar-Kolar, R. R., Ryan, E. E., \& Runyon, M. K. (2008). Child sexual abuse: From prevention to self-protection. Child Abuse Review, 17, 3654. doi:10.1002/car.1012

Kim, K., Noll, J. G., Putnam, F. W., \& Trickett, P. K. (2007). Psychosocial characteristics of non-offending mothers of sexually abused girls: Findings from a prospective, multigenerational study. Child Maltreatment, 12, 338-351. doi:10.1177/1077559507305997

Kinsey, A. C., Pomeroy, W. B., Martin, C. E., \& Gebhard, P. H. (1953). Sexual behaviour in the human female. Philadelphia: WB Saunders \& Co.

Ko, S. F., \& Cosden, M. A. (2001). Do elementary school-based child abuse prevention programs work? A high school follow-up. Psychology in the Schools, 38, 57-66. doi:10.1002/1520-6807(200101)38:1<57::AID-PITS6>3.0.CO;2-W 
Laaksonen, T., Sariola, H., Johansson, A., Jern, P., Varjonen, M., von der Pahlen, B., Sandnabba, K., \& Santtila, P. (2011). Changes in the prevalence of child sexual abuse, its risk factors, and their associations as a function of age cohort in a Finnish population sample. Child Abuse \& Neglect, 35, 480-490.

doi:10.1016/j.chiabu.2011.03.004

Leclerc, B., Wortley, R., \& Smallbone, S. (2010). An exploratory study of victim resistance in child sexual abuse:Offender modus operandi and victim characteristics. Sexual Abuse, 22, 25-41. doi:10.1177/1079063209352093

Leifer, M., Kilbane, T., \& Kalick, S. (2004). Vulnerability or resilience to intergenerational sexual abuse: The role of maternal factors. Child Maltreatment, 9, 78-91. doi:10.1177/1077559503261181

Leventhal, J. M. (1987). Programs to prevent sexual abuse: what outcomes should be measured? Child Abuse \& Neglect, 11, 169-171.

Lewin, L., \& Bergin, C. (2001). Attachment behaviors, depression, and anxiety in nonoffending mothers of child sexual abuse victims. Child Maltreatment, 6, 365-375. doi:10.1177/1077559501006004009

MacIntyre, D., \& Carr, A. (1999). Evaluation of the effectiveness of the stay safe primary prevention programme for child sexual abuse. Child Abuse \& Neglect, 23, 1307-1325. doi:10.1016/S0145-2134(99)00092-7

MacMillan, H. L., MacMillan, J. H., Offord, D. R., Griffith, L., \& MacMillan, A. (1994). Primary prevention of child sexual abuse: A critical review. Part II. The Journal of Child Psychology and Psychiatry, 35, $857-876$.

MacMillan, H. L., Wathen, C. N., Barlow, J., Fergusson, D. M., Leventhal, J. M., \& Taussig, H. N. (2009). Interventions to prevent child maltreatment and associated impairment. The Lancet, 373, 250-266. doi:10.1016/S0140-6736(08)61708-0 
Masson, J. (1992). The assault on truth: Freud and child sex abuse. London: Fontana

McCloskey, L. A., \& Bailey, J. A. (2000). The intergenerational transmission of risk for child sexual abuse. Journal of Interpersonal Violence, 15, 1019-1035. doi:10.1177/088626000015010001

McLeigh, J. D., McDonell, J. R., \& Melton, G. B. (2015). Community differences in the implementation of strong communities for children. Child Abuse \& Neglect, 41, 97112. doi:10.1016/j.chiabu.2014.07.010

Melton, G. B. (1992). The improbability of prevention of sexual abuse. In Willis, D. J., Holden, E. W., \& Rosenberg, M. S. (Eds.), Prevention of child maltreatment: Developmental and ecological perspectives (pp. 168-189). New York: John Wiley \& Sons.

Meston, C. M., Heiman, J. R., \& Trapnell, P. D. (1999). The relation between early abuse and adult sexuality. Journal of Sex Research, 36, 385395.doi:10.1080/00224499909552011

Mustaine, E. E., Tewksbury, R., Huff-Corzine, L., Corzine, J., \& Marshall, H. (2014). Community characteristics and child sexual assault: Social disorganization and age. Journal of Criminal Justice, 42, 173. doi:10.1016/j.jcrimjus.2013.06.016

Noar, S. M., Benac, C. N., \& Harris, M. S. (2007). Does tailoring matter? meta-analytic review of tailored print health behavior change interventions. Psychological Bulletin, 133, 673-693. doi:10.1037/0033-2909.133.4.673

Olafson, E., Corwin, D. L., \& Summit, R. C. (1993). Modern history of child sexual abuse awareness: Cycles of discovery and suppression. Child Abuse \& Neglect, 17, 7-24. doi:10.1016/0145-2134(93)90004-O

Pelcovitz, D., Adler, N. A., Kaplan, S., Packman, L., \& Krieger, R. (1992). The failure of a school-based child sexual abuse prevention program. Journal of the American 
Academy of Child \& Adolescent Psychiatry, 31, 887-892. doi:10.1097/00004583199209000-00017

Pérez-Fuentes, G., Olfson, M., Villegas, L., Morcillo, C., Wang, S., \& Blanco, C. (2013).

Prevalence and correlates of child sexual abuse: A national study. Comprehensive Psychiatry, 54, 16-27. doi:10.1016/j.comppsych.2012.05.01

Plummer, C. (1999). The history of child sexual abuse prevention: A practitioner's perspective. Journal of Child Sexual Abuse, 7, 77-95. doi:10.1300/J070v07n04_06

Prescott, D., Plummer, C., \& Davis, G. (2010). Recognition, response, and resolution:

Historical responses to rape and child molestation. The Prevention of Sexual Violence: A Practitioner's Sourcebook. Holyoke, MA: NEARI.

Ramirez, C., Pinzon-Rondon, A. M., \& Botero, J. C. (2011). Contextual predictive factors of child sexual abuse: The role of parent-child interaction. Child Abuse \& Neglect, 35, 1022-1031. doi:10.1016/j.chiabu.2011.10.004

Renk, K., Liljequist, L., Steinberg, A., Bosco, G., \& Phares, V. (2002). Prevention of child sexual abuse: Are we doing enough? Trauma, Violence, \& Abuse, 3, 68-84. doi:10.1177/15248380020031004

Reppucci, N. D., Haugaard, J. J., \& Antonishak, J. (2005) Is there empirical evidence to support the effectiveness of child sexual abuse prevention programs? In D. R. Loseke, R. J. Gelles, \& M. M. Cavanaugh (Eds.), Current controversies on family violence (pp. 271-284). Thousand Oaks, CA: Sage Publications

Roberts, R., O'Connor, T., Dunn, J., \& Golding, J. (2004). The effects of child sexual abuse in later family life; mental health, parenting and adjustment of offspring. Child Abuse \& Neglect, 28, 525-545. doi:10.1016/j.chiabu.2003.07.006 
Russell, D. E. H. (1983). The incidence and prevalence of intrafamilial and extrafamilial sexual abuse of female children. Child Abuse \& Neglect, 7, 133-146. doi:10.1016/0145-2134(83)90065-0

Russell, D. E. H. (1999). The secret trauma: Incest in the lives of girls and women. New York: Basic Books.

Sanders, M. R., Montgomery, D. T., \& Brechman-Toussaint, M. L. (2000). The mass media and the prevention of child behavior problems: The evaluation of a television series to promote positive outcomes for parents and their children. The Journal of Child Psychology and Psychiatry and Allied Disciplines, 41, 939-948. doi:10.1017/S0021963099006198

Sanderson, J. (2004). Child-Focused Sexual Abuse Prevention Programs: How Effective Are They in Preventing Child Abuse? (Vol. 5). Brisbane, QLD: Crime and Misconduct Commission.

Smaal, Y. (2013). Historical perspectives on child sexual abuse, part 1. History Compass, 11, 702-714. doi:10.1111/hic3.12083

Smallbone, S., Marshall, W. L., \& Wortley, R. (2008). Preventing child sexual abuse: Evidence, policy and practice. Hoboken: Willan.

Smallbone, S. W., Wortley, R. K., (2000). Child Sexual Abuse in Queensland: Offender Characteristics \& Modus Operandi. Queensland: Qld Crime Commission.

Swift, C. F. \& Ryan-Finn, K. (1995). Perpetrator prevention: Stopping the development of sexually abusive behaviour. In C. F. Swift (Ed.), Sexual Assault and Abuse: Sociocultural Context of Prevention. (pp. 13-44). New York: Haworth Press.

Testa, M., Hoffman, J. H., \& Livingston, J. A. (2011). Intergenerational transmission of sexual victimization vulnerability as mediated via parenting. Child Abuse \& Neglect, 35, 363-371. doi:10.1016/j.chiabu.2011.01.010 
Tewksbury, R., Mustaine, E. E., \& Covington, M. (2010). Offender presence, available victims, social disorganization and sex offense rates. American Journal of Criminal Justice, 35, 1-14. doi:10.1007/s12103-010-9070-6

Topping, K. J., \& Barron, I. G. (2009). School-based child sexual abuse prevention programs: A review of effectiveness. Review of Educational Research, 79, 431-463. doi:10.3102/0034654308325582

Tutty, L. M. (1992). The ability of elementary school children to learn child sexual abuse prevention concepts. Child Abuse \& Neglect, 16, 369-384. doi:10.1016/01452134(92)90046-T

Tutty, L. M. (1997). Child sexual abuse prevention programs: Evaluating who do you tell. Child Abuse \& Neglect, 21, 869-881. doi:10.1016/S0145-2134(97)00048-3

Tutty, L. M. (2000). What children learn from sexual abuse prevention programs: Difficult concepts and developmental issues. Research on Social Work Practice, 10, 275-300. doi:10.1177/104973150001000301

Wakefield, M. A., Loken, B., \& Hornik, R. C. (2010). Use of mass media campaigns to change health behaviour. The Lancet, 376, 1261-1271. doi:10.1016/S01406736(10)60809-4

Walsh, K., Berthelsen, D., Nicholson, J. M., Brandon, L., Stevens, J., \& Rachele, J. N. (2013). Child sexual abuse prevention education: A review of school policy and curriculum provision in Australia. Oxford Review of Education,39, 649-680. doi: $10.1080 / 03054985.2013 .843446$

Walsh, K., Brandon, L., \& Chirio, L. (2012). Mother-child communication about sexual abuse prevention. Journal of Child Sexual Abuse, 21, 399-421. doi:10.1080/10538712.2012.675424 
Walsh, K., Zwi, K., Woolfenden, S., \& Shlonsky, A. (2015). School-based education programmes for the prevention of child sexual abuse. Evidence-Based Child Health: A Cochrane Review Journal,4, doi: 10.1002/14651858.CD004380.pub3

Wortley, R., \& Smallbone, S. (2006). Situational prevention of child sexual abuse (Vol. 19). Monsey, NY: Criminal Justice Press.

Wurtele, S. K. (1987). School-based sexual abuse prevention programs: A review. Child Abuse \& Neglect, 11, 483-495. doi:10.1016/0145-2134(87)90074-3

Wurtele, S. K. (2009). Preventing sexual abuse of children in the twenty-first century: Preparing for challenges and opportunities. Journal of Child Sexual Abuse, 18, 1-18. doi:10.1080/10538710802584650

Wyatt, G. E. (1985). The sexual abuse of Afro-American and white-American women in childhood. Child Abuse \& Neglect, 9, 507-519. doi:10.1016/0145-2134(85)90060

Zeuthen, K., \& Hagelskjær, M. (2013). Prevention of child sexual abuse: Analysis and discussion of the field. Journal of Child Sexual Abuse, 22, 742-760. doi:10.1080/10538712.2013.811136

Zwi, K., Woolfenden, S., Wheeler, D., O'Brien, T., Tait, P., \& Williams, K. (2008). Cochrane review: School-based education programmes for the prevention of child sexual abuse. Evidence-Based Child Health: A Cochrane Review Journal, 3, 603-634. doi:10.1002/ebch.264 